\title{
CAPÍTULO 18: APROVEITAMENTO ENERGÉTICO DE BAGAÇO DE LARANJA E CASCA DE MARACUJÁ IN NATURA DA AGROINDÚSTRIA DE SUCO PARA PRODUÇÃO METANO
}

\section{CHAPTER 18: ENERGY USE OF ORANGE BAGASSE AND PASSION FRUIT PEEL IN NATURA THE OF JUICE AGROINDUSTRY FOR METANE PRODUCTION}

\section{CAPÍTULO 18:USO ENERGÉTICO DE ENVASES DE NARANJA Y PASION EN NATURA DE LA AGROINDUSTRIA DE JUGO PARA LA PRODUCCIÓN DE METANO}

Liliana Andréa dos Santos ${ }^{1}$; Carollinni Roberta de Melo Oliveira ${ }^{2}$; André Felipe de Melo Sales Santos ${ }^{3}$; José Fernando Thomé Jucá ${ }^{4}$

\section{RESUMO}

DOI : $\underline{\text { https://doi.org/10.31692/978-65-88970-19-5.265-279 }}$

$\mathrm{Na}$ produção de suco e polpas são gerados cerca de $50 \%$ de resíduos como cascas, sementes, caroços, os quais são subvalorizados ou descartados como forma de rejeito na maior parte do Brasil. Contudo, estes resíduos de frutas podem ser valorizados como fonte de recursos utilizando a biomassa para a produção de energia por tecnologias renováveis como a digestão anaeróbia. O trabalho teve como objetivo avaliar o potencial de geração de metano de bagaço de laranja e casca de maracujá in natura utilizando o lodo industrial como inóculo através de ensaio de potencial bioquímico de metano (BMP). Os resíduos de frutas e o lodo industrial foram caracterizados em termos de $\mid \mathrm{pH}$, sólidos voláteis, umidade, sólidos totais e condutividade elétrica. O Potencial Bioquímico de Metano (BMP) foi avaliado em reatores em batelada, de $250 \mathrm{~mL}$, em condições mesofílicas $\left(37 \pm 2{ }^{\circ} \mathrm{C}\right)$, sob agitação $(60$ rpm), durante 60 dias, utilizando inóculo anaeróbio (lodo industrial) e com adição de bicarbonato de sódio $\left(1 \mathrm{~g} \mathrm{NaHCO}_{3}\right)$. Em termos de resultados de caracterização, o bagaço de laranja e casca de maracujá apresentaram $\mathrm{pH}$ ácido, elevado teor de umidade e sólidos voláteis. O lodo industrial apresentou $\mathrm{pH}$ neutro, alta umidade e sólidos voláteis. Em termos de composição de biogás gerado apresentou concentrações médias de metano de 67 a $73 \%$ para substratos e inóculo. O potencial de

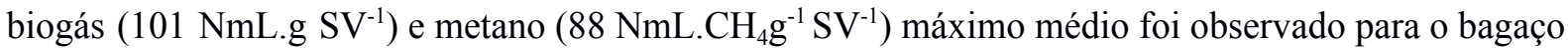
de laranja, com de biogás utilizando lodo anaeróbio industrial. A digestão anaeróbia de resíduos de frutas é uma alternativa viável para valorização e aproveitamento de seu potencial energético, proporcionando ganhos à cadeia produtiva.

Palavras-Chave: resíduos de frutas, digestão anaeróbia, biogás

\section{RESUMEN}

En la producción de jugos y pulpas, se genera alrededor del $50 \%$ de los residuos, como cáscaras, semillas, semillas, que son infravalorados o descartados como una forma de desperdicio en la mayor parte de Brasil. Sin embargo, estos residuos de frutas pueden valorarse como fuente de recursos utilizando biomasa para la producción de energía mediante tecnologías renovables como la digestión anaeróbica. El objetivo de este trabajo fue evaluar el potencial de generación de metano a partir de

\footnotetext{
${ }^{1}$ Profa.Doutora no Mestrado Profissional em Tecnologia Ambiental, ITEP, liliana.andrea.santos@gmail.com.br

${ }^{2}$ Bacharel em Ciências Biológicas e Ciências Ambientais, UFPE, rcarolinni@gmail.com

${ }^{3}$ Prof. Doutor do Departamento de Tecnologia Rural, UFRPE, andrefelipeufrpe@outlook.com

${ }^{4}$ Prof. Doutor do Departamento de Engenharia Civil, UFPE, jftjucah@gmail.com
} 
orujo de naranja y cáscara de maracuyá in natura utilizando lodos industriales como inóculo mediante una prueba de potencial bioquímico de metano (BMP). Los residuos de frutas y lodos industriales se caracterizaron en términos de $\mathrm{pH}$, sólidos volátiles, humedad, sólidos totales y conductividad eléctrica. El Potencial Bioquímico del Metano (BMP) se evaluó en reactores discontinuos, de $250 \mathrm{~mL}$, en condiciones mesofílicas $\left(37 \pm 2^{\circ} \mathrm{C}\right)$, bajo agitación $(60 \mathrm{rpm})$, durante 60 días, utilizando inóculo anaeróbico (lodo industrial) y con adición de bicarbonato de sodio $\left(1 \mathrm{~g} \mathrm{de} \mathrm{NaHCO}_{3}\right)$. En cuanto a los resultados de la caracterización, el orujo de naranja y la piel de maracuyá presentaron pH ácido, alto contenido de humedad y sólidos volátiles. La industria de lodos presentó pH neutro, alta humedad y sólidos volátiles. En cuanto a la composición del biogás generado, presentó concentraciones promedio de metano de 67 a $73 \%$ para sustratos e inóculo. Se observó el potencial máximo de biogás (101 NmL.g SV ${ }^{-1}$ ) y metano ( $88 \mathrm{NmL} . \mathrm{CH} 4 \mathrm{~g}^{-1} \mathrm{SV}^{-1}$ ) para el bagazo de naranja, con biogás utilizando lodos anaeróbicos industriales. La digestión anaeróbica de los residuos de frutas es una alternativa viable para la valorización y aprovechamiento de su potencial energético, aportando ganancias a la cadena productiva.

Palabras clave: residuos de frutas, digestión anaeróbica, biogás.

\begin{abstract}
In the production of juice and pulps, about $50 \%$ of residues are generated, such as peels, seeds, seeds, which are undervalued or discarded as a form of waste in most of Brazil. However, these fruit residues can be valued as a source of resources using biomass to produce energy by renewable technologies such as anaerobic digestion. The objective of this work was to evaluate the potential of methane generation from orange bagasse and passion fruit peel in natura using industrial sludge as an inoculum using a methane biochemical potential test (BMP). Fruit waste and industrial sludge were characterized in terms of $\mid \mathrm{pH}$, volatile solids, moisture, total solids, and electrical conductivity. The Biochemical Potential of Methane (BMP) was evaluated in batch reactors, of $250 \mathrm{~mL}$, under mesophilic conditions $\left(37 \pm 2^{\circ} \mathrm{C}\right)$, under agitation $(60 \mathrm{rpm})$, for 60 days, using anaerobic inoculum (industrial sludge) and with addition of sodium bicarbonate $\left(1 \mathrm{~g} \mathrm{NaHCO}_{3}\right)$. In terms of characterization results, orange bagasse and passion fruit peel showed acid $\mathrm{pH}$, high moisture content and volatile solids. The sludge industry presented neutral $\mathrm{pH}$, high moisture, and volatile solids. In terms of the composition of biogas generated, it presented average methane concentrations of 67 to $73 \%$ for substrates and inoculum. The maximum biogas (101 NmL.g SV $\left.{ }^{-1}\right)$ and methane $\left(88 \mathrm{NmL} \mathrm{CH}_{4} \mathrm{~g}^{-1} \mathrm{SV}^{-1}\right)$ potential was observed for orange bagasse, with biogas using industrial anaerobic sludge. The anaerobic digestion of fruit waste is a viable alternative for the valorization and use of its energy potential, providing gains to the production chain.
\end{abstract}

Keywords: fruit waste, anaerobic digestion, biogas.

\title{
1. INTRODUÇÃO
}

O Brasil ocupa a terceira colocação no ranking de produção de frutas, representando cerca de $6 \%$ da produção mundial, produzindo cerca de 41 milhões de toneladas de frutas frescas em 2019 (IBGE, 2019). No segmento de frutas processadas o Brasil se destaca na produção de néctares, drinques e polpas de frutas, sucos (SANTOS, 2019).

$\mathrm{Na}$ produção de suco e polpas são gerados cerca de 50\% de resíduos em base úmida (cascas, sementes, caroços), os quais são descartados ou subvalorizados na maior parte do país, mesmo sendo fonte de vitaminas e nutrientes essenciais (DO NASCIMENTO FILHO; 
FRANCO, 2015). Estes resíduos de frutas são destinado a aterros sanitários ou usados como alimentação animal. Devido aos altos custos de armazenamento estes resíduos podem se tornar um problema ambiental devido à elevada facilidade de fermentação e biodegradabilidade, essas características podem contribuir para problemas negativos em sistemas tradicionais de disposição de resíduos sólidos, como emissões de gases de efeito estufa e geração de lixiviado em aterros sanitários (EDWIGES et al., 2018). Entretanto, estes resíduos que antes eram descartados pela agroindústria de suco, podem ser valorizados como fonte de recursos utilizando a biomassa para a produção de energia por tecnologias renováveis como a digestão anaeróbia (SANTOS, 2019; SANTOS et al., 2020).

A digestão anaeróbia converte a biomassa em biogás $\left(\mathrm{CH}_{4}, \mathrm{CO}_{2}\right)$ que pode ser aproveitado para produção de energia elétrica, gás natural, combustível veicular, entre outros, além de produzir biofertilizante que pode ser utilizado na agricultura (SILVA; FRANCISCO, 2010; SANTOS, 2016).

Desta forma, o objetivo deste estudo foi avaliar o potencial de geração de metano de bagaço de laranja (BLI) e casca de maracujá (CMI) in natura utilizando o lodo industrial (LI) como inóculo através de ensaio de potencial bioquímico de metano (BMP).

\section{FUNDAMENTAÇÃO TEÓRICA}

A fruticultura é um dos setores da economia de maior destaque do agronegócio brasileiro, principalmente na produção de frutas frescas (in natura), industrialização de sucos e néctares (OCDE-FAO, 2015). A produção de frutas em 2017 foi mais de 865 milhões de toneladas de frutas no mundo (OCDE-FAO, 2015). O Brasil figura entre os principais produtores mundiais de frutas, com colheitas superiores a 40 milhões de toneladas em 2018, estando entre os três maiores produtores (China, Índia e Brasil) do mundo.

No Brasil, a laranja e o maracujá têm se destacado no setor de fritucultura para utilização na indústria de sucos (SANTOS, 2019).

Os citrus são as frutas mais produzidas e consumidas no mundo, principalmente laranjas, tangerinas, limas e limões (MEDEIROS, 2014). O Brasil é líder mundial na produção e exportação de laranjas, com aproximadamente 17.750 milhões de toneladas na safra de 2018/2019 (USDA, 2019). 85\% da produção de laranja in natura no Brasil é utilizada pela indústria de sucos, sendo o maior produtor e exportador de suco de laranja do 
mundo (SILVA, 2014).

Outra fruta com destaque no cenário brasileiro é o maracujá, sendo o Brasil o maior produtor e consumidor de maracujá do mundo, com $95 \%$ da produção nacional de maracujá sendo representado pelo maracujazeiro-azedo (Passiflora edulis Sims) (JANZANTTI; MONTEIRO, 2014; JESUS et al., 2016). Em 2017, o país produziu 554 mil toneladas, com destaque para região Nordeste que é a maior produtora nacional com mais de 337 mil toneladas (IBGE, 2019). Cerca de 60\% do maracujá é utilizado para consumo in natura, 40\% na indústria de suco, principalmente para extração de polpa para fabricação de suco. O suco de maracujá ocupa o terceiro lugar em escala nacional, perdendo apenas para o suco de laranja e caju representando $8,5 \%$ do volume de sucos prontos para beber consumidos no país (GRECO, 2014).

Grandes quantidades de resíduos são gerados a partir de atividades agrícolas, florestais e municipais, com destaque para a agroindustria que gera elevada quantidade de resíduos a partir do processamento de frutas para produção de sucos (SANTOS, 2019). Após a extração, cerca de 40\%-60\% da fruta (laranja, maracujá) é descartada na forma de bagaço, o resíduo resultante do processamento dessas frutas (casca, semente e polpa), podem ser prensados, desidratados e peletizados para facilitar o manuseio e transporte (CYPRIANO et al., 2017).

Os resíduos gerados após o processamento são destinados a aterros sanitários ou usados como ração animal, entretanto, devido aos altos custos de armazenamento e transporte muitas vezes doados ou tratados como rejeitos, descartando seus potenciais usos, contribuindo para a poluição ambiental INFANTE et al., 2013; SANTOS, 2019).

Ao mesmo tempo, os resíduos podem se tornar um problema ambiental decorrendo em custos para as agroindústrias, estes podem ser fontes de recursos, mediante processamento tecnológico adequado, com destaque para produção de biopolímeros, biocombustíveis (etanol, biogás), enzimas, produtos químicos e fertilizantes (KALYANI et al., 2013; CUI et al., 2015).

Além disso, esses resíduos podem ser utilizados como fonte de biomassa devido as suas características de elevada umidade, elevado teor de carboidratos (polímeros solúveis, insolúveis) e fácil biodegradação, ideal para conversão em biocombustíveis biológicos, como etanol e biogás (TAGHIZADEH-ALISARAEI et al., 2017).

A digestão anaeróbia, como alternativa de valorização energética de resíduos agroindustriais, vem ganhando interesse nos últimos anos visto representar uma fonte de 
energia com baixa emissão de carbono e de aproveitamento mais sustentável dos resíduos orgânicos (EBNER et al., 2015). Dentre os benefícios do uso destaca-se a aplicação em pequena e grande escala e a geração de combustível gasoso renovável (SILVA et al., 2021). Assim, a digestão anaeróbia representa uma solução alternativa para o tratamento de resíduos agroindustriais de frutas, gerando o biogás, que pode ser utilizado como fonte de energia alternativa, obtendo ainda biofertilizante com capacidade de aproveitamento agroindustrial (SANTOS et al., 2019).Vários pesquisadores têm investigado o potencial de fermentação de frutas e vegetais comuns para demonstrar as vantagens de usar o processo de digestão anaeróbica para produzir energia através do biogás (FORGACS et al., 2012; CALABRÒ et al., 2016; CARVALHO et al., 2017; SILVA et al., 2019; SANTOS et al., 2020). No entanto, existem poucos trabalhos com o uso do maracujá como fonte de biomassa para digestão anaeróbia, sendo o número de publicações ainda mínimo, embora essa fruta tenha elevada importância para o mercado brasileiro.

No entanto, as características especificas dos resíduos de frutas podem ser vistas como desvantagem e representar desafios para aplicação eficaz da digestão anaeróbia. Tais características incluem $\mathrm{pH}$ ácido (3-4), conteúdo orgânico de ST (10\%), sólidos voláteis (6-18\%), relação $\mathrm{C} / \mathrm{N}(20)$, umidade $>80 \%$ e alto teor de material lignocelulósico (RUIZ; FLOTATS, 2016) Entretanto, a utilização desses resíduos como fonte de biomassa na digestão anaeróbia é viável, desde que seja utilizado um inóculo anaeróbio eficiente, contribuindo de forma integral para o seu gerenciamento (RUIZ; FLOTATS, 2014).

\section{METODOLOGIA}

\subsection{Obtenção dos resíduos de frutas e lodo industrial}

As amostras de laranja (BLI) e maracujá (CMI) in natura foram obtidas de um mercado local localizado na cidade do Recife no Estado de Pernambuco.

A laranja e o maracujá in natura antes da realização dos ensaios, foram cortados manualmente em pedaços, em seguida, foi extraído o suco da laranja e retirada a polpa do maracujá, posteriormente as amostras foram trituradas em liquidificador para obtenção do bagaço de laranja e casca de maracujá.

O inóculo anaeróbio utilizado foi lodo industrial (LI) coletado de um reator UASB (upflow anaerobic sludge blanket) de $1000 \mathrm{~m}^{3}$ para produção de energia elétrica, a partir biogás, utilizando como biomassa a vinhaça bruta com adição de lodo granular industrial. 


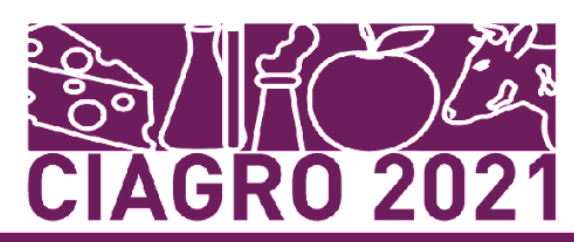

Foram coletadas amostras de 5 litros do lodo anaeróbio, armazenadas em bombonas de polietileno e conservadas a $19 \pm 1^{\circ} \mathrm{C}$ antes da realização dos ensaios.

\subsection{Caracterização do bagaço de laranja, casca de maracujá e inóculo anaeróbio}

Antes da realização dos ensaios físico-químicos, os resíduos BLI, CMI foram colocados em estufa a $65^{\circ} \mathrm{C}$ para secagem até a estabilização da umidade, em seguida, foram triturados em moinho de facas (tipo Willye, marca SPLabor), homogeneizados, peneirados e armazenados em temperatura ambiente $\left(26 \pm 2{ }^{\circ} \mathrm{C}\right)$.

Os substratos BLI, CMI e o lodo industrial (LI) foram caracterizados através das análises de o teor umidade, sólidos totais (ST) e sólidos totais voláteis (SV), conforme WHO (1978). O Potencial hidrogeniônico (pH) de acordo com a metodologia NBR 10006 (ABNT, 2004); as análises de pH e condutividade elétrica foram realizadas antes e após a finalização dos ensaios BMP. Todas as análises foram realizadas em triplicata.

\subsection{Ensaio do potencial bioquímico de metano (BMP)}

O teste de Potencial de Bioquimico de Metano (BMP) seguiu a metodologia de Santos et al. (2020).

Para o teste BMP (batelada), foram utilizados frascos de borossilicato, com volume total de $250 \mathrm{~mL}$, constituídos de tampa de nylon rosqueada, com anéis de vedação. A tampa do frasco continha acoplada duas válvulas-agulha, sendo uma para alívio da pressão do biogás gerado ou para a inserção de $\mathrm{N}_{2}$ (purga do $\mathrm{O}_{2}$, no início do ensaio), e outra, onde fica instalado um manômetro mecânico (100 kPa), para monitoramento da pressão do biogás no interior do reator.

A quantidade de BLI e CMI inseridos nos reatores foram de 13,5 g (2,16 g/seca), 11,2 $\mathrm{g}(2,45 \mathrm{~g} / \mathrm{seca})$ úmida, respectivamente, conforme a Tabela 1. A quantidade de inóculo anaeróbio (LI) adicionado em cada frasco foi de 26,5 g. A quantidade de bicarbonato de sódio utilizado foi de $1 \mathrm{~g}$ de acordo com Santos et al. (2020). Para manter a DQO de $2 \mathrm{~g}$. $\mathrm{L}^{-1} \mathrm{e}$ um volume útil de $200 \mathrm{~mL}$ para cada configuração, dentro do reator foi inserido água destilada. Em todos os reatores, foi mantido o headspace de $50 \mathrm{~mL}$, representando $20 \%$ do volume do reator. O experimento foi realizado em triplicata, considerando ainda um branco, no qual apenas foi adicionada água destilada e inóculo.

Tabela 1: Experimental configurations of BMP assays. 


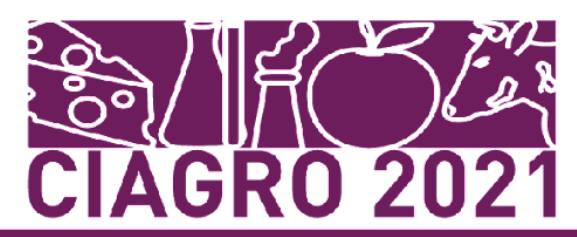

\begin{tabular}{lcccc} 
Configurações & $\begin{array}{c}\text { Substrato } \\
\text { (g/úmida) }\end{array}$ & Inóculo $(\mathbf{g})$ & Água $(\mathbf{m L})$ & Headspace $(\mathbf{m L})$ \\
\hline BLI+LI & 13,5 & 26,5 & 160 & 50 \\
CMI+LI & 11,2 & 26,5 & 160 & 50 \\
LI & - & 26,5 & 160 & 50 \\
\hline
\end{tabular}

Fonte: Própria (2021).

O preenchimento do reator foi de acordo com a metodologia de Santos et al. (2020), seguindo a sequência: adição do resíduo, adição do inóculo anaeróbio, complementação do volume com água destilada (calculada), adição do bicarbonato de sódio, aferição inicial da condutividade elétrica e $\mathrm{pH}$ do conteúdo do reator, fechamento do reator e válvulas, envolvimento do reator em papel alumínio. Depois que os reatores foram preenchidos e fechados, os manômetros foram retirados e realizado a introdução de $\mathrm{N}_{2}$ com as válvulas-agulha abertas (proporcionar condições anaeróbias ideais para degradação do substrato), por 2 minutos. Em seguida, as válvulas de saída e entrada de gás foram fechadas e os manômetros recolados aos reatores mantendo-se uma pressão em todos os frascos de 20 KPa (SANTOS et al., 2020). Em seguida, os reatores foram mantidos em mesa incubadora (TECNAL TE 424$)$ com controle de temperatura $\left(37 \pm 2^{\circ} \mathrm{C}\right)$ e com agitação orbital (60 rpm), por 60 dias. Os ensaios foram realizados em triplicata.

O volume de biogás acumulado foi analisado indiretamente através da medição da pressão acumulada de biogás obtida no monitoramento diário conforme a metodologia de Ivanova et al. (2008). O monitoramento da pressão dos reatores ocorreu durante 60 dias.

A composição do biogás foi avaliada a partir do $7^{\circ}$ dia do experimento, mantendo o headspace dos reatores nos dois últimos dias, antecedentes da medição, sem descarte, para aumentar o volume de biogás disponível para a injeção no cromatógrafo (triplicata) (SANTOS, 2019).

Para avaliar a composição do biogás $\left(\mathrm{CH}_{4}, \mathrm{CO}_{2}\right)$ foi utilizando um cromatógrafo gasoso (APPA GOLD), com detector de condutibilidade térmica (TCD), com uma coluna (Porapak “N”), que utiliza o $\mathrm{H}_{2}$ como gás de arraste, a uma temperatura do forno de $60^{\circ} \mathrm{C}$. Foi utilizado um gás padrão $\left(60 \%\right.$ de $\mathrm{CH}_{4}$ e $40 \%$ de $\mathrm{CO}_{2}$ ), para calibração do cromatógrafo. Para o tratamento dos dados foi utilizado o Sistema de Aquisição de Dados Cromatográficos N2000 Chromatostation. 


\subsubsection{Análise do potencial de biogás e $\mathrm{CH}_{4}$}

$\mathrm{O}$ potencial de biogás e metano $\left(\mathrm{Y}_{\mathrm{m}}\right)$ foi obtido através da subtração do volume acumulado de biogás/metano das configurações (substrato + inóculo) pelo volume acumulado do branco do inóculo respectivo, dividido pela massa (em grama sólidos voláteis) do substrato de acordo com a Equação 1.

$$
Y_{m}=\frac{V A_{s}-V A_{i}}{V S_{g}}
$$

$-\mathrm{Y}_{\mathrm{m}}=$ Potencial de biogás ou metano $\left(\mathrm{NmL} \cdot \mathrm{g}^{-1} \mathrm{SV}\right)$

- $V A_{s}=$ Volume acumulado de biogás/metano da configuração estudada (NmL)

- $V A_{i}$ V Volume acumulado de biogás/metano do branco do inóculo (NmL)

$-\mathrm{VS}_{\mathrm{g}}=$ Concentração inicial de VS do substrato seco $\left(\mathrm{g}^{-1} \mathrm{SV}\right)$

\section{RESULTADOS E DISCUSSÃO}

\subsection{Caracterização dos substratos in natura, inóculo anaeróbio e conteúdo inicial e final}

\section{do Teste BMP}

A Tabela 2 apresenta os resultados da caracterização em termos de $\mathrm{pH}$, umidade, ST, $\mathrm{SV}$, dos substratos in natura (BLI, CMI) e inóculo (LI).

Tabela 2: Caracterização de substratos in natura e inóculo utilizados

$\begin{array}{lccc}\text { Parâmetro } & \text { BLI } & \text { CMI } & \text { LI } \\ \text { pH } & 3,4 & 3,5 & 7,0 \\ \text { Umidade (\%) } & 87 & 90 & 89 \\ \text { ST (\%) } & 13 & 10 & 10 \\ \text { SV (\%) } & 94 & 90 & 76\end{array}$


Os substratos (BLI, CMI) e o inóculo (LI) apresentaram elevado teor de umidade, sendo favorável para facilitar o contato dos micro-organismos com substrato e o transporte de nutrientes durante a digestão anaeróbia (Santos et al., 2020). O BLI apresentou sólidos totais (13\%) superior em comparação a CMI (10\%) e LI (10\%). Resultados similares de teor de umidade (85 a 88\%) foram encontrados na literatura para bagaço de laranja e casca de maracujá (DEUS et al., 2014, ZHAO et al., 2016; SANTOS et al. 2020).

Os sólidos voláteis de BLI e CMI variaram de 90 a 94\%, cujos valores estão próximos aos encontrados na literatura para estes tipos de substratos. Valores superiores foram encontrados por Santos et al. (2020) que obtiveram valores de sólidos voláteis de 94\% e 95\% para casca de maracujá e bagaço de laranja secos, respectivamente. Resíduos de frutas e vegetais normalmente possuem elevado teor de sólidos voláteis, devido à elevada fração orgânica presente, sendo benéfico a digestão anaeróbia (CALABRÒ et al., 2015, RUIZ e FLOTATS, 2016). O inóculo LI obteve SV de 76\%, considerado elevado para lodos anaeróbios.

$\mathrm{O} \mathrm{pH}$ dos substratos estudado apresentaram valores na faixa ácida $(3,4$ a 3,5), típicos para resíduos de bagaço de laranja e casca de maracujá in natura. Valores semelhantes de $\mathrm{pH}(3,0$ a 4,2) foram encontrados por outros autores para estes tipos de substratos (DEUS et al., 2014; CARVALHO et al., 2017; SANTOS et al., 2020). O inóculo LI obteve pH neutro $(7,0)$, normalmente relatado para inóculos anaeróbios em equilibrio.

Diversos autores ao estudarem inóculos anaeróbios encontaram $\mathrm{pH}$ na faixa neutra (6,6-8,0) (STEINMETZ et al., 2016; CARVALHO et al., 2017; SANTOS et al., 2020).

Na Tabela 3 são apresentadas as características das configurações dos ensaios BMPs, antes e após os testes.

Tabela 3: Caracterização inicial e fina dos conteúdos dos teste BMP das configurações estudadas

Parâmetro

$\mathrm{pH}$ inicial

$\mathrm{pH}$ final

Condutividade inicial $\left(\mu \mathrm{s} . \mathrm{cm}^{-1}\right)$

Condutividade final $\left(\mu \mathrm{s} . \mathrm{cm}^{-1}\right)$
BLI+LI

8,3

7,6

474

6953

\section{CMI+LI}

6,8

7,7

1495

6796 . 
Legenda: BLI (Bagaço de laranja in natura); CMI (Casca de maracujá in natura); LI (Lodo industrial).

Fonte: Própria (2021).

Os valores iniciais $(8,3,6,8)$ e finais $(7,6,7,0)$ médios de $\mathrm{pH}$, antes e após a digestão anaeróbia das configurações estudadas encontram-se próxima a faixa de $\mathrm{pH}(6,4$ a 7,5$)$ recomendada para produção de metano (CHERNICHARO, 1997).

Valores similares de $\mathrm{pH}$ final $(7,6)$ foram obtidos por outros autores ao estudaram a digestão de bagaço de laranja in natura com adição de digestivo líquido em reatores em batelada (1,1 litros) em condição mesofilica (CALABRÓ; PANZERA, 2018). O BLI+LI apresentou $\mathrm{pH}(8,3)$ final elevado, valores de $\mathrm{pH}$ acima de 8,3 devem ser evitados, pois podem inibir a fase metanogênica durante a digestão anaeróbia (CHERNICHARO, 1997).

Em termos de condutividade elétrica, em todas houve aumento da condição inicial para final em todas as configurações estudadas nos testes BMP, indicando que o substrato está sendo degradado pelos micro-organismos anaeróbios (ROCHA, 2009; SANTOS, 2020).

A condutividade elétrica final (6953 a $\left.6953 \mu \mathrm{s} . \mathrm{cm}^{-1}\right)$ de BLI e CMI com adição de LI

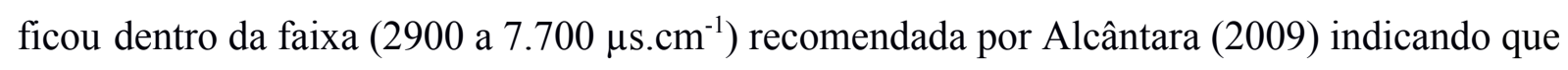
digestão anaeróbia na última fase (metanogênese).

Santos et al. (2020) obtiveram condutividade elétrica de 5358 e $7402 \mu \mathrm{s} . \mathrm{cm}^{-1}$ para bagaço de laranja e casca de maracujá com adição de lodo anaeróbio, respectivamente.

\subsection{Avaliação da produção, potencial e percentagem de biogás e metano de bagaço de laranja e casca de maracujá in natura}

Em termos de produção de biogás acumulado, considerando o valor médio das configurações de resíduos de frutas in natura, a configuração BLI+LI, apresentou volume acumulado de biogás (654 NmL) superior em relação combinação CMI+LI (415 NmL) (Figura 1).

Figura 1. Volume de biogás acumulado $(\mathrm{NmL})$ das configurações testadas 


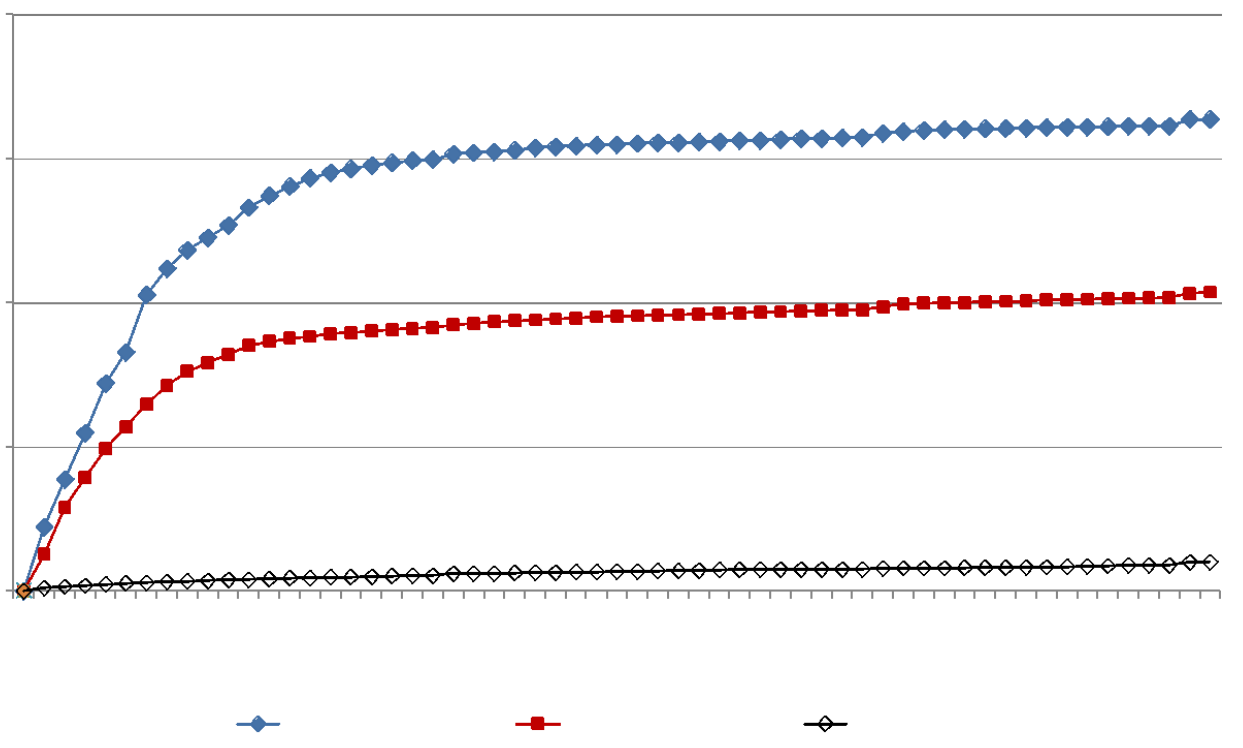

Legenda: BLI (Bagaço de laranja in natura); CMI (Casca de maracujá in natura); LI (Lodo industrial).

Fonte: Própria (2021).

Em relação ao volume acumulado de $\mathrm{CH}_{4}$ a configuração BLI+LI (181 NmL) apresentou o melhor resultado em comparação a CMI+LI que apresentou o menor volume acumulado de $\mathrm{CH}_{4}(111 \mathrm{NmL})$ (Figura 2).

Por volta do $25^{\circ}$ dia de realização do experimento, mais de $80 \%$ do total do biogás acumulado havia sido produzido em todas as configurações.

$\mathrm{O}$ volume acumulado de biogás e $\mathrm{CH}_{4}$ do inóculo (LI) sem adição de substrato foi de 41 NmL, $21 \mathrm{NmL}$, respectivamente.

Figura 2: Volume de metano $(\mathrm{NmL})$ das configurações estudadas

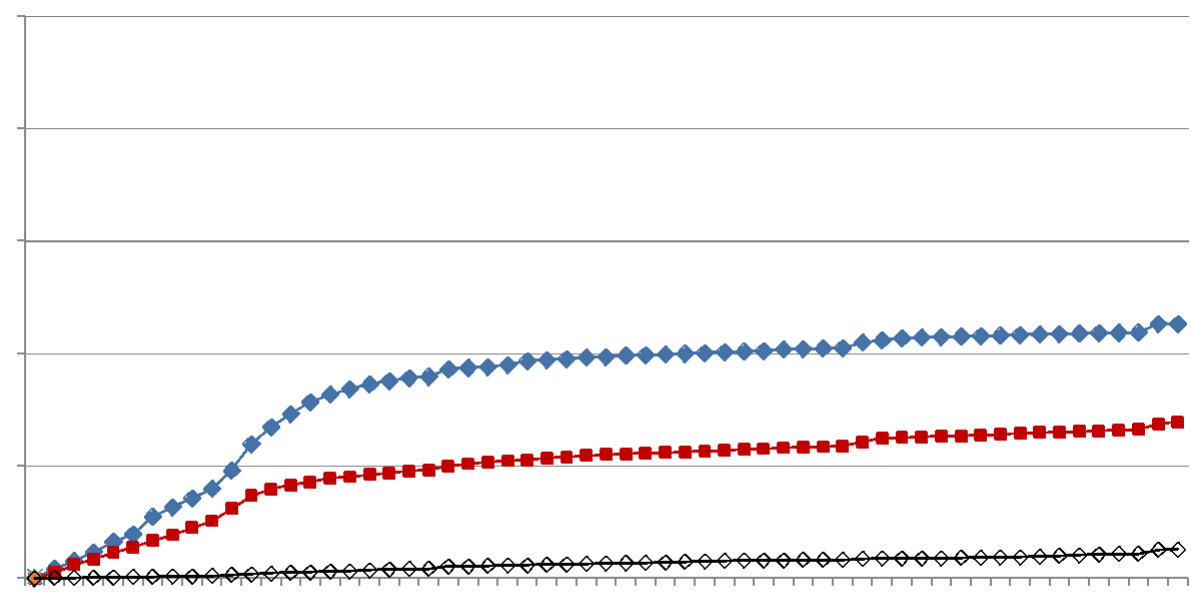

Legenda: BLI (Bagaço de laranja in natura); CMI (Casca de maracujá in natura); LI (Lodo de industrial). 


\section{Fonte: Própria (2021).}

Pode-se observar que em níveis de produção de volume de metano na digestão com bagaço de laranja in natura, o inóculo LI acelerou a etapa de hidrólise, consequentemente houve maior produção de metano em comparação a CMI+LI (Figura 2).

Na Figura 3 estão apresentados o potencial de geração e metano das configurações estudadas.

O melhor potencial de geração de biogás $\left(298 \mathrm{NmL} \cdot \mathrm{g}^{-1} \mathrm{SV}\right)$ e metano $\left(88 \mathrm{NmL} \cdot \mathrm{CH}_{4} \mathrm{~g}^{-1}\right.$ $\mathrm{SV}$ ) foi da combinação do bagaço de laranja in natura com lodo industrial (BLI+LI).

Resultados similares de potencial de metano $\left(86 \mathrm{NmL} \mathrm{CH}_{4} \cdot \mathrm{g}^{-1} \mathrm{SV}\right)$ foram encontrados por Santos et al. (2018) ao estudarem a digestão anaeróbia de bagaço de laranja seco com adição de lodo industrial utilizando reatores em batelada sob temperatura de $37^{\circ} \mathrm{C}$ por 47 dias. Entretanto, outros autores obtiveram potencial de geração de metano $\left(360 \mathrm{NmL}\right.$. $\left.\mathrm{CH}_{4} \mathrm{~g}^{-1} \mathrm{SV}\right)$ superior ao avaliarem a digestão anaeróbia de bagaço de laranja in natura com adição de inóculo anaeróbio (digestato líquido) em reatores batelada em condições mesófilas durante 30 dias (CALABRÓ; PANZERA, 2018). A configuração CMI+LI obteve o menor potencial de biogás (162 NmL.g $\left.{ }^{-1} \mathrm{SV}\right)$ e metano (48 $\left.\mathrm{NmL} \mathrm{CH}_{4} \mathrm{~g}^{-1} \mathrm{SV}\right)$ em comparação a BLI+LI. Resultados superiores foram encontrados por outros autores na literatura. Santos et al. (2020) obtiveram potencial de geração de metano (115 NmL. $\left.\mathrm{CH}_{4} \mathrm{~g}^{-1} \mathrm{SV}\right)$ superior ao estudarem a digestão anaeróbia de casca de maracujá seca com adição de lodo industrial em condições mesófilas $\left(37^{\circ} \mathrm{C}\right)$. Zhao et al. (2016) avaliaram a digestão de casca de maracujá com lodo de esgoto em reatores em batelada a temperatura de $37^{\circ} \mathrm{C}$ obtiveram potencial superior de metano de $195 \mathrm{NmL} \mathrm{CH}_{4} \cdot \mathrm{g}^{-1} \mathrm{SV}$.

Figura 3: Potencial de geração de biogás e metano $\left(\mathrm{NmL} \cdot \mathrm{g}^{-1} \mathrm{SV}\right)$ das configurações estudadas

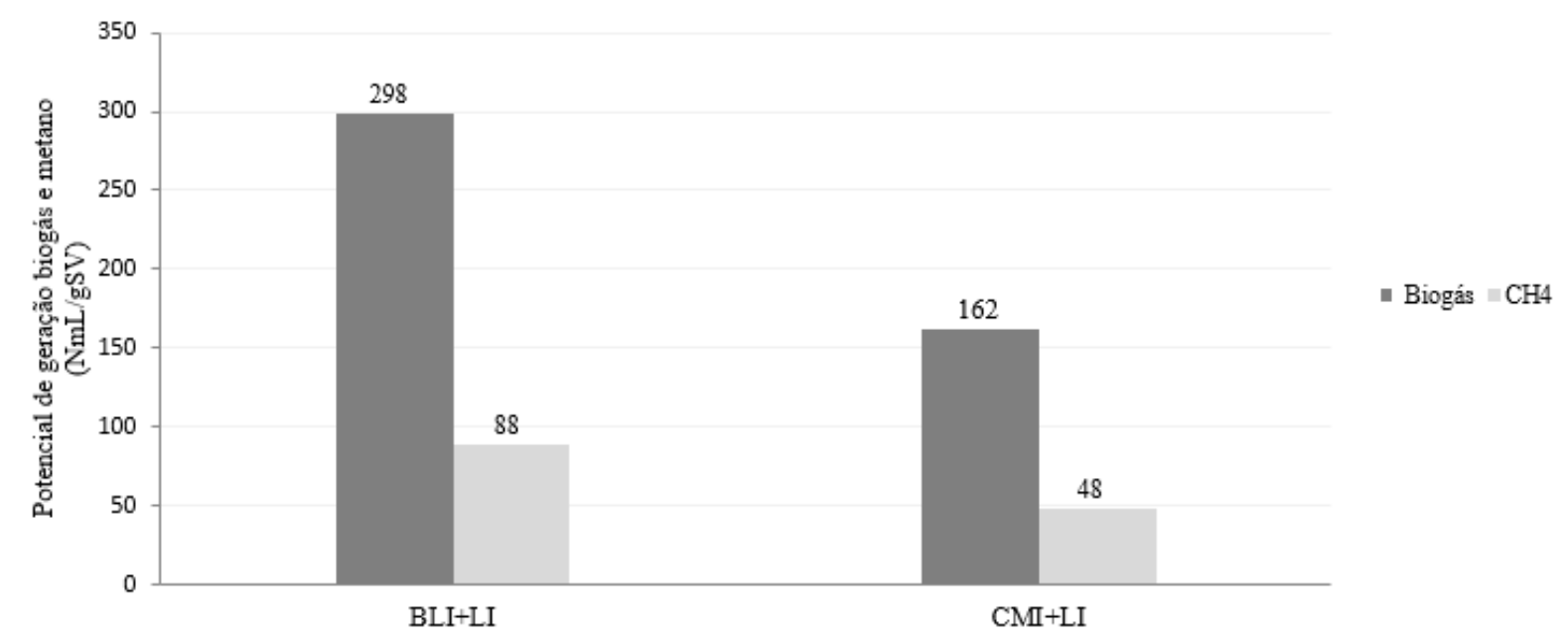

Legenda: BLI (Bagaço de laranja in natura); CMI (Casca de maracujá in natura); LI (Lodo de industrial). Fonte: Própria (2019). 
Em termos composição do biogás, as configurações (BLI+LI, CMI+LI) estudadas apresentaram percentagem de $\mathrm{CH}_{4}$ elevada, variando de 64 a $71 \%$, atestando a eficiência da digestão anaeróbia desses resíduos (Figura 4) (SANTOS, 2019). A configuração CMI+LI apresentou percentagem de metano (71\%) superior em comparação a BLI+LI (64\%). Os valores de percentagem de metano foram semelhantes aos encontrados na literatura, variando 58 a 73\% de para resíduos de laranja e maracujá (EDWIGES et al., 2018; SILVA et al., 2019; SANTOS et al., 2020). O lodo industrial apresentou elevada percentagem de metano (73\%) típico para inóculos anaeróbios que possui micro-organismos produtores de metano como as Arqueas metanogênicas.

Figura 4: Porcentagem média de metano, em volume, presente em cada configuração estudada

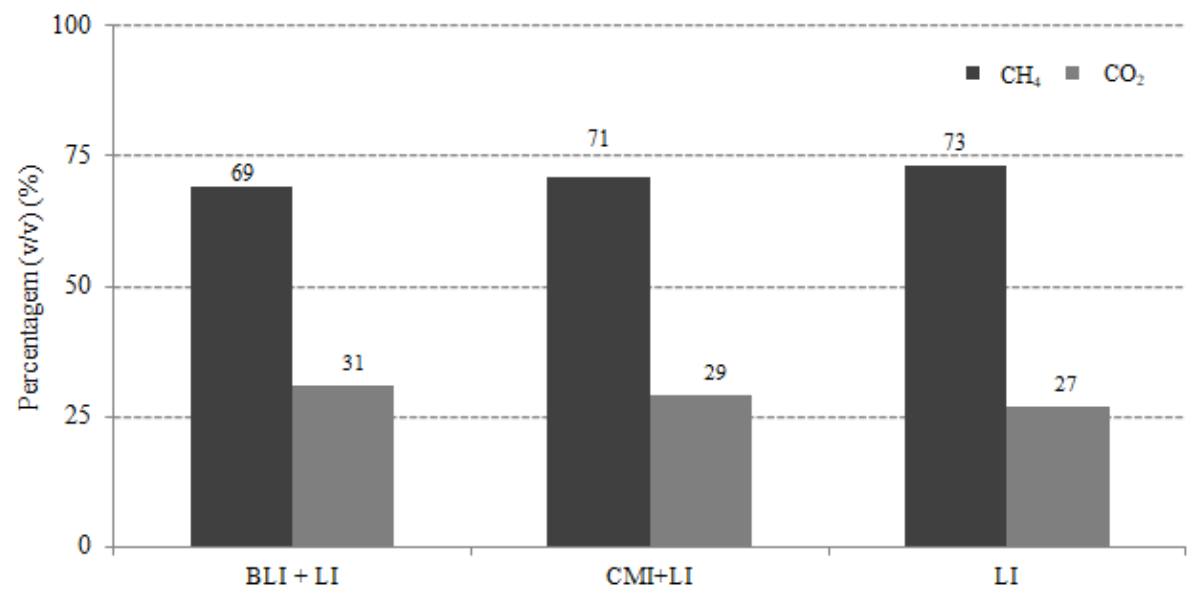

Legenda: BLI (Bagaço de laranja in natura); CMI (Casca de maracujá in natura); LI (Lodo de industrial). Fonte: Própria (2021).

\section{CONSIDERAÇÕES FINAIS}

O potencial máximo de geração de biogás $\left(298 \mathrm{NmL} \cdot \mathrm{g}^{-1} \mathrm{SV}\right)$ e metano $\left(88 \mathrm{NmL} \cdot \mathrm{g}^{-1}\right.$ SV) foi observado para o bagaço de laranja in natura com adição lodo industrial. O bagaço de laranja e casca de maracujá apresentaram elevada percetagem de metano (67-71\%), indicando que o resíduo pode ser utilizado como biomassa para fins energéticos. Destaca-se que os ganhos com a valorização energética desses resíduos para o setor agroindustrial contribui para sua competitividade e sustentabilidade dessa importante cadeia produtiva.

\section{REFERÊNCIAS}


ABNT. NBR 10.006. Procedimento para obtenção de extrato solubilizado de resíduos sólidos.

Rio de Janeiro. 2004.

ALCÂNTARA, P. B. Avaliação da influência da composição dos resíduos sólidos urbanos no comportamento de aterros simulados. 2007. 366 f. Tese (Doutorado em Engenharia Civil) - Universidade Federal de Pernambuco, Recife.

CHERNICHARO, C. A. L. Princípios do Tratamento Biológico de Águas Residuárias Reatores Anaeróbios, v. 5.2 ed. Belo Horizonte: Segrac, DESA, UFMG, 1997, 246 p.

CUI, Y.; DONG, X.; TONG, J.; LIU, S. Degradation of Lignocellulosic Components in Un-pretreated Vinegar Residue Using an Artificially Constructed Fungal Consortium. BioResources, [s.l], v.10, n. 2, p. 3434-3450, 2015.

CALABRÒ, P. S.; PONTONI, L.; PORQUEDDU, I.; GRECO, R.; PIROZZI, F.; MALPEI, F. Effect of the concentration of essential oil on orange peel waste biomethanization: Preliminary batch results, Waste Management, Oxford, v. 48, p. 440- 447, 2015.

CALABRÒ, P.S.; PANZERA, M. F. Biomethane production tests on ensiled orange peel waste. Thermal Science and Engineering Progress, [s.l], v. 35, n. 1, p.130-136, 2017.

CARVALHO, A.; R. FRAGOSO, R.; J. GOMINHO, J.; E. DUARTE, E.; Effect of Minimizing d-Limonene Compound on Anaerobic Codigestion Feeding Mixtures to Improve Methane Yield. Waste Biomass Valor, [s.l], p. 1-9, 2017.

CYPRIANO, D. Z.; DA SILVA, L. L.; MARIÑO, M. A.; TASIC, L. A Biomassa da Laranja e seus Subprodutos. Revista Virtual Quimica, [s.l], v. 9, n. 1, p. 176-191, 2017.

DO NASCIMENTO FILHO, W. B.; FRANCO, C. R. Avaliação do Potencial dos Resíduos Produzidos através do Processamento agroindustrial no Brasil. Revista Virtual de Quimica, [s.l], v. 7, n. 6, p. 1968-1987, 2015.

EBNER, J. H.; LABATUT, R. A.; RANKIN, M. J.; PRONTO, J. L.; GOOCH, C. A.; WILLIAMSON, A. A.; TRABOLD, T.A. Lifecycle Greenhouse Gas Analysis of an Anaerobic Codigestion Facility Processing Dairy Manure and Industrial Food Waste. Environmental Science \& Technology, [s.l], v. 47, n. 18, p. 11199-11208, 2015.

EDWIGES, T.; FRARE, L.; MAYER, B.; LINS, TRIOLO, L.; J. M.; FLOTATS, X.; COSTA, M. S. S. M. Influence of chemical composition on biochemical methane potential of fruit and vegetable waste. Waste Management, Oxford, v. 71, p. 618-625, 2018.

FORGACS, G.; MOHAMMAD POURBAFRANI, M.; NIKLASSON, C.; TAHERZADEHA, M. J.; HOV'ATHA, I. S. A. Methane production from citrus wastes: process development and cost estimation. Journal of Chemical Technology Biotechnology, [s.l], v. 87, n.250-255, 2012.

GRECO, S. M. L. Caracterização físico-química e molecular de genótipos de maracujá 
azedo cultivados no Distrito Federal. 2014. 149 f. Tese (Doutorado em Agronomia) Faculdade de Agronomia e Medicina Veterinária, Brasília.

IBGE-INSTITUTO BRASILEIRO DE GEOGRAFIA E ESTATÍSTICA. Levantamento sistêmico de produção agrícola. Rio de Janeiro, 2017. Disponível em: $<$ http://www.sidra.ibge.gov.br>. Acesso em: 12 out. 2019.

INFANTE, J.; SELANI, M. M.; TOLEDO, N. M. V.; SILVEIRA-DINIZ, M. F.; ALENCAR, S. M.; SPOTO, M. H. F. Atividade antioxidante de resíduos agroindustriais de frutas tropicais. Brazilian Journal of Food Nutrition., Araraquara, v. 24, n. 1, 2013.

IVANOVA, L.K., RICHARDS, D.J., SMALLMAN, D.J. The long-term settlement of landfill waste. Waste and Resource Management. Proceedings of the Institution of Civil Engineers, [s.l], p. 121-133, 2008.

JANZANTTI N. S.; MONTEIRO M. Changes in the aroma of organic passion fruit (Passiflora edulis Sims f. flavicarpa Deg.) during ripeness. Lwt-Food Science Technology, [s.l], v. 59, p. 612-624, 2014.

KALYANI, D.; LEE, K. M.; KIM, T. S.; LI, J.; DHIMAN, S. S.; KANG, Y. C.; LEE, J. K. Microbial consortia for saccharification of woody biomass and ethanol Fermentation. Fuel, [s.l], v. 107, p. 815-822, 2013.

JESUS, O. N.; SOARES, T. L.; GIRARDI, E. A.; ROSA, R. C. R.; OLIVEIRA, E. J.; NETO, A. J. C.; SANTOS, V. T.; OLIVEIRA, J. R. P. Evaluation of intraspecific hybrids of yellow passion fruit in organic farming. African Journal of Agricultural Research, [s.l], v. 11. n. 24, p. 2129-2138, 2016.

MEDEIROS, O. M. Enriquecimento nutricional por bioconversão de resíduos agroindustriais para utilização na alimentação animal. 2007. $121 \mathrm{f}$. Tese (Doutorado em Engenharia de processos) - Universidade Federal de Campina Grande, Campina Grande.

OCDE-Organização das Nações Unidas para Agricultura e Alimentação (FAO). Agricultura brasileira: Perspectivas e Desafios. 54 p, 2015.

ROCHA, L. SOATES, T do C, ARAUJO. Avaliação de Biodigestor para uso domiciliar na reciclagem de resíduos semi-sólidos orgânicos. Encontro de Ensino, Pesquisa e Extensão, Presidente Prudente, 5 a 8 de outubro, 2009.

RUIZ, B.; FLOTATS, X.; Citrus essential oils and their influence on the anaerobic digestion process: An overview. Waste Management, Oxford, v. 34, n. 11, p. 2063-2079, 2014.

RUIZ, B.; FLOTATS, X. Effect of limonene on batch anaerobic digestion of citrus peel waste. Journal Biochemical Engineering, [s.l], v. 109, p. 9-18, 2016.

SANTOS, L. A.; SANTOS, A. F. M. S.; VALENÇA, R. B.; JUCÁ, J. F. T.; OLIVEIRA, C. R. M. Produção de biogás a partir de bagaço de laranja. Revista GEAMA, Recife, v. 4, n. 3, p. 022-027, 2018. 
SANTOS, I. V. V. S. Biodigestão anaeróbia dos resíduos da agroindústria de citrus. 2016. 47 f. Dissertação (Mestrado Profissional em Energia da Biomassa) - Universidade Federal de Alagoas, Rio Largo.

SANTOS, L. A. Potencial de geração de biogás a partir de resíduos agroindustriais de frutas. 2019. 185 f. Tese (Doutorado em Engenharia Civil) - Universidade Federal de Pernambuco, Recife.

SANTOS, L. A.; VALE NÇ A, R. B.; SILVA, L. C. S.; HOLAND A, S. H. B.; SILV A, A.F.V.; JUCÁ, J. F. T.; SANTOS, A. F. M. S. Methane generation potential through an aerobic digestion of fruit waste. Journal of Cleaner Production, [s.l], v. 256, p. 120389, 2020.

SILVA, N. P.; FRANCISCO, A. C. Geração de energia elétrica a partir de dejetos suínos: um estudo de caso em uma propriedade rural na região oeste do estado do Paraná. Nucleus, [s.l], v. 7, n. 2 , p. $65-82,2010$.

SILVA, C. E. F. Avaliação do potencial de uso de resíduos do processamento de frutas na produção de etanol 2G. 2014. 101 f. Dissertação (Mestrado Engenharia Química) Universidade Federal de Alagoas, Maceió.

SILVA, A. F. V.; SANTOS, L. A.; VALENÇA, R. B.; PORTO, T. S.; MOTTA, M. A. S.; GOMES, G. J. C.; JUCÁ, J.F.T.; SANTOS, A. F. M. S. Cellulase production to obtain biogas from passion fruit (Passiflora edulis) peel waste hydrolysate. Journal of Environmental Chemical Engineering, [s.l], v. 7, n. 6, p. 103510, 2019.

SILVA, T. H. L.; SANTOS, L. A.; CAROLINNI ROBERTA DE MELO OLIVEIRA, C. R. M.; PORTO, T. S.; JUCÁ, J. F. T.; SANTOS, A. F. M. S. Determination of methane generation potential and evaluation of kinetic models in poultry wastes. Biocatalysis and Agricultural Biotechnology, [s.l], v. 32, p. 101936, 2021.

STEINMETZ, R. L. R.; MEZZARI, M. P.; SILVA, M. L. B.; KUNZ, A.; AMARAL, A. C.; TÁPPARO, D. C.; SOARES, H. M. Enrichment and acclimation of an anaerobic mesophilic microrganism's inoculum for standardization of BMP assays. Bioresource Technology, Essex, Essex, v. 219, p. 21-28, 2016.

TAGHIZADEH-ALISARAEIA, A.; HOSSEINIA, S. H.; GHOBADIANB, B.; MOTEVALIC, A. Biofuel production from citrus wastes: A feasibility study in Iran. Renewable and Sustainable Energy, [s.l], v. 69, p. 1100-1112, 2017.

USDA- United States Department of Agriculture. Agricultural Statistics Annual 2013. Washington, 2019.

WHO - International Reference Center for Waste Disposal. Methods of analysis of sewage sludge solid wastes and compost. Suíça. 1978.

ZHAO, C.; YAN, H.; LIU, Y.; HUANG, Y.; ZHANG, R.; CHEN, C.; LIU, G. Bio-energy conversion performance, biodegradability, and kinetic analysis of different fruit residues during discontinuous anaerobic digestion. Waste Management, Oxford, v. 52, p. 295-301, 2016. 
